\title{
Diagnóstico e caracterização das marcenarias na cidade de Viçosa, MG
}

\section{Assessment and characterization of joineries in the city of Viçosa, MG}

\author{
Ricardo Ribeiro Alves ${ }^{1}$; Carla Priscilla Távora Cabral²; Maria Odete Alves de \\ Souza $^{3}$; Graziela Baptista Vidaurre ${ }^{2}$; Andréia Colli; ${ }^{4}$ José de Castro Silva ${ }^{5 *}$
}

Resumo

O setor florestal não é constituído apenas por grandes empresas, como as de celulose e papel ou de painéis reconstituídos, mas também por pequenas empresas, muitas das vezes estritamente familiares, como as marcenarias. O presente trabalho teve por objetivo a identificação, diagnóstico e caracterização das marcenarias de Viçosa, Estado de Minas Gerais. Delimitaram-se, como objeto de estudo, as empresas de marcenaria da cidade, principalmente, pertencentes ao antigo Núcleo de Marceneiros. Elaborou-se um questionário para buscar informações sobre a madeira utilizada, gerenciamento interno e qualificação dos funcionários, maquinário, produtos, mercado, divulgação dos produtos e perspectivas do setor. Verificou-se que tanto os empresários quanto os funcionários possuem baixo grau de instrução, além de falta de design próprio dos produtos. Sua produção era apenas sob encomenda, com utilização intensa, no processo produtivo, de madeira maciça, notadamente oriunda de florestas nativas. Seus produtos eram heterogêneos, indo desde o mobiliário até utilidades do meio rural. A concorrência, principalmente a informal, representava o maior empecilho para o desenvolvimento do setor, além dos produtos seriados comercializados em estabelecimentos comerciais, oriundos de outras localidades, a preços mais reduzidos. Concluiu-se que o setor de marcenaria, em Viçosa, necessita de uma maior qualificação, tanto gerencial quanto técnica, para aperfeiçoamento da atividade. Além disso, torna-se necessário uma maior organização através de associações e apoio de entidades como o Sebrae local, e de uma maior divulgação dos produtos aos consumidores da região.

Palavras-chave: Mercado moveleiro. Móveis sob encomenda. Madeira maciça.

\begin{abstract}
The forestry sector is not only formed by large companies, such as pulp and paper or reconstituted panels, but also by small businesses, and often strictly family businesses, as joineries. This study aimed to identify, assess and characterize joineries in Viçosa, Minas Gerais. The object of study was limited to the city's joinery businesses, mainly the ones belonging to the former Joiner's Association. A questionnaire was drawn up to obtain information on the used wood, internal management and employee training, machinery, products, market, product advertising and prospects for the sector. It was found that both entrepreneurs and workers have low educational level and lack their own product design. They were producing only ordered products with intensive use of solid wood particularly from native forests. Products were heterogeneous, ranging from furniture to farm utilities. Competition, mainly the
\end{abstract}

1 Administrador, Doutorando em Ciência Florestal - Departamento de Engenharia Florestal - Universidade Federal de Viçosa (UFV). E-mail: ricardo.alves@ufv.br

2 Engenheira Florestal, Doutoranda em Ciência Florestal - Departamento de Engenharia Florestal - Universidade Federal de Viçosa (UFV).

3 Arquiteta e Urbanista, M.S. Ciência Florestal - Departamento de Engenharia Florestal - Universidade Federal de Viçosa (UFV).

${ }^{4}$ Engenheira Florestal, M.S. Ciência Florestal - Departamento de Engenharia Florestal - Universidade Federal de Viçosa (UFV).

${ }_{5}$ Engenheiro Florestal, D.S. Engenharia Florestal. Professor adjunto do Departamento de Engenharia Florestal - Universidade Federal de Viçosa (UFV).

* Autor para correspondência 
informal, represented the biggest obstacle to sector development, as well as serialized products from other locations sold in shops at lower prices. It was concluded that the joinery sector in Viçosa needs greater skill levels, both technical and managerial, to improve the activity. Moreover, the sector needs better organization through associations and support of agencies such as local Sebrae, and wider product advertising targeting consumers in the region.

Key words: Furniture market. Made-to-order furniture. Solid wood.

\section{Introdução}

A indústria de móveis caracteriza-se pela reunião de diversos processos de produção (seriado e sob encomenda), envolvendo diferentes matériasprimas e uma diversidade de produtos finais. Pode ser segmentada, principalmente em função dos materiais com que estes produtos são confeccionados (madeira, metal etc), bem como de acordo com o uso a que são destinados (GORINI, 1999).

A madeira maciça foi a primeira matéria-prima utilizada na fabricação de móveis. Ela possui, como característica, a beleza de suas diferentes disposições de fibras e colorações, alta resistência física e mecânica, durabilidade e usinabilidade, podendo ser emoldurada, torneada ou entalhada. Com o avanço das tecnologias e dos materiais, as chamadas "madeiras de lei" (jacarandá, mogno, imbuia, cerejeira, freijó, marfim etc) passaram a ser mais utilizadas na forma de lâminas aplicadas sobre painéis (aglomerado, compensado, MDF etc.) otimizando o uso desta matéria-prima, cada vez mais escassa.

Nos últimos anos, a indústria moveleira passou por uma profunda transformação, para sobreviver à concorrência, as empresas sentiram a necessidade de ter algo além de uma boa estrutura física ou de equipamentos de última geração. As fábricas viram-se obrigadas a contar com equipes de profissionais qualificados e comprometidos com o negócio. Para isso, iniciou-se uma busca incessante de colaboradores que reunissem competências técnicas e comportamentais diferenciadas. Nesta realidade, um fator tornou-se indispensável para o desenvolvimento das empresas: a presença de profissionais criativos. Esta criatividade ajudaria a fazer frente às pressões, reagir às ameaças, resolver os problemas e descobrir as oportunidades (MAJOLA, 2005).

No Brasil, a indústria moveleira é muito fragmentada e caracteriza-se principalmente por dois aspectos: elevado número de micro e pequenas empresas e grande absorção de mão-de-obra, sendo a maior parte desqualificada. No entanto, nos últimos anos tem alcançado um crescimento considerável, principalmente devido à abertura da economia e à ampliação do mercado interno que, juntamente com a redução da inflação e de seus custos indiretos, têm introduzido novos consumidores, antes excluídos do mercado (LIMA, 1998; VALENÇA; PAMPLONA; SOUTO, 2002).

Em Minas Gerais, segundo o Instituto Euvaldo Lodi - IEL (2003), dos 853 municípios que compõem o Estado, 408 estão inseridos no setor "madeira e mobiliário", empregando 62.063 pessoas. Há uma grande concentração de indústrias, principalmente nas proximidades de Belo Horizonte, Ubá e Divinópolis, que podem ser denominadas pólos moveleiros, representando $44,9 \%$ do total de estabelecimentos do setor no Estado. Alguns desses pólos são mais organizados e podem ser considerados arranjos produtivos locais, possuindo intensidades diferenciadas em termos de potencial de desenvolvimento.

A cidade de Viçosa está localizada na Zona da Mata mineira e próxima à cidade de Ubá, considerado o principal pólo moveleiro de Minas Gerais e um dos sete mais importantes do país (FERNANDES; OLIVEIRA JÚNIOR, 2002). Apesar da pequena distância que separa estas duas localidades, a indústria moveleira viçosense apresenta características bem diferentes e não aproveita as vantagens oferecidas pela proximidade do pólo de Ubá para alavancar seu 
desenvolvimento e produção. Neste contexto, surge a necessidade de se conhecer as características das marcenarias de Viçosa a fim de se verificar suas principais potencialidades e as deficiências que prejudicam o seu crescimento.

O presente trabalho teve como objetivo fazer um diagnóstico e caracterização das marcenarias de Viçosa, de forma a fornecer subsídios para seu desenvolvimento. Especificamente, procurou-se avaliar as madeiras utilizadas pelas marcenarias para a confecção dos móveis, o tipo de maquinário utilizado pelas marcenarias, bem como os produtos principais oriundos de sua produção, analisar a estrutura interna das marcenarias, enfatizando a qualificação e treinamento de seus proprietários e funcionários e avaliar o mercado e as perspectivas para o setor.

\section{Material e Métodos}

Para a consecução do trabalho, delimitaram-se como objeto de estudo, principalmente as empresas que pertenciam ao antigo Núcleo de Marceneiros de Viçosa, entidade que congregava os empresários do setor e empresas do ramo de marcenaria vinculadas a ela. Ao todo foram pesquisadas 17 marcenarias da cidade, algumas das quais, inclusive, na condição de informalidade e não pertencentes àquela entidade.

Elaborou-se um questionário para coleta de informações sobre as espécies florestais utilizadas, gerenciamento interno e qualificação dos funcionários, maquinário, produtos, mercados, divulgação dos produtos e perspectivas do setor. Este questionário foi respondido pelos responsáveis pelas marcenarias que, na maioria dos casos, eram o próprio dono da empresa.

Os dados referentes às respostas do questionário foram organizados e sistematizados por meio de tabulação, utilizando-se planilha eletrônica, e foram apresentados na forma de gráficos e tabelas.

\section{Resultados e Discussão}

Características gerais das marcenarias estudadas

As marcenarias estudadas na cidade de Viçosa apresentam, unanimemente, o processo de produção da forma sob encomenda. São caracterizadas, em quase sua totalidade, por microempresas (até 19 empregados) sendo que apenas uma delas é considerada empresa de pequeno porte - EPP (de 20 a 99 empregados), segundo a classificação adotada pelo SERVIÇO BRASILEIRO DE APOIO ÀS MICRO E PEQUENAS EMPRESAS - SEBRAE (2006). As marcenarias têm em média dezoito anos de funcionamento e sua origem é familiar, passando de pai para filho o exercício da profissão. Verificouse que a maioria dos proprietários das marcenarias apresentava idade acima de quarenta anos (Figura 1). Tal fato pode indicar que a atividade de marcenaria constituiu a principal ou até mesmo a única atividade profissional em suas vidas, face à idade média do setor verificado anteriormente.

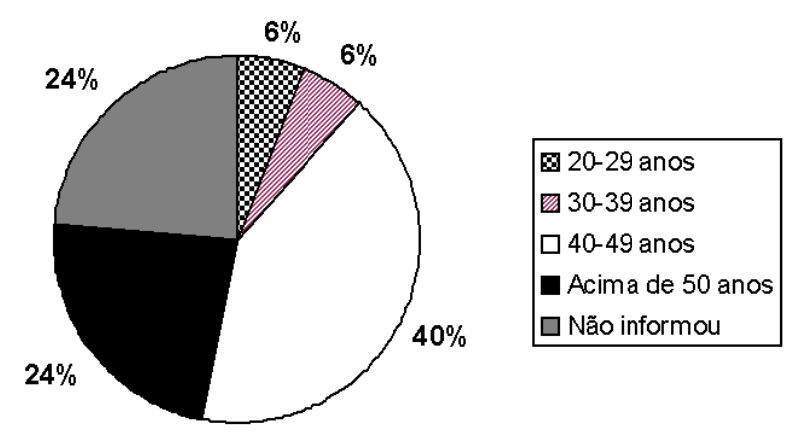

Gráfico 1. Média de idade dos proprietários de marcenaria da cidade de Viçosa, MG.

Verificou-se também, que a maioria dos empresários possuía o ensino fundamental (antigo primeiro grau). Cerca de $12 \%$ dos empresários concluíram ocurso superior(Figura2), demonstrando que a atividade de marcenaria local está concentrada nas mãos de pessoas com baixo grau de instrução, mesmo estando suas empresas localizadas em uma cidade universitária. Com relação aos empregados, 
verificou-se que a situação é ainda pior, visto que a grande maioria $(76,47 \%)$ não concluiu o ensino fundamental. Os resultados são semelhantes aos obtidos por Crocco et al. (2001), em estudo realizado no pólo moveleiro de Ubá, demonstrando que a mão-de-obra na indústria moveleira em toda região é composta de empregados com pouco grau de instrução.
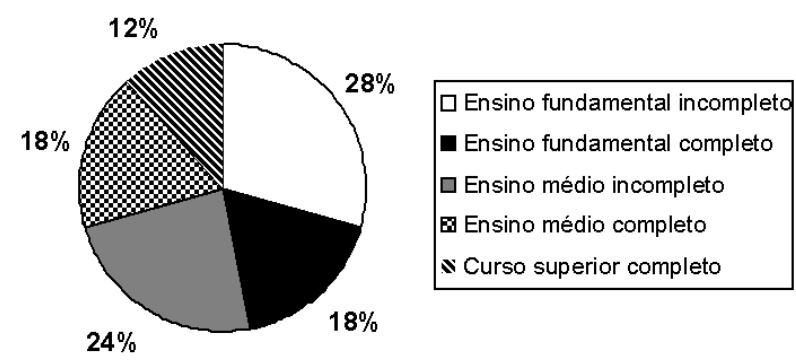

Gráfico 2. Grau de instrução dos proprietários de marcenaria em Viçosa, MG.

Além do baixo grau de instrução desta mão-deobra, verificou-se que apenas $24 \%$ das marcenarias realizaram algum tipo de treinamento de seus empregados, sendo citadas as entidades mais atuantes nesta questão, como o SEBRAE local e o SENAI de Ubá. A maioria dos empresários enfatizou que seus empregados são treinados na própria empresa, por meio da "prática do dia-a-dia", pois alegam ser difícil encontrar um marceneiro profissional no mercado local. Todavia, reconheceram a importância de um treinamento mais adequado e a necessidade, principalmente, de cursos referentes ao acabamento de móveis.

No aspecto referente à segurança no trabalho, verificou-se que os funcionários não usavam Equipamento de Segurança no Trabalho (EPI) e o ambiente de trabalho era inadequado às atividades desenvolvidas, sendo pouco arejado e havendo uma luminosidade precária nos locais onde se encontravam as máquinas de alta periculosidade, expondo os funcionários a um maior risco de acidentes.

\section{Principais matérias-primas utilizadas}

As marcenarias de Viçosa apresentaram um maior consumo de madeira maciça em relação ao uso de painéis, como compensado, MDF e laminados. Isto poderia ser explicado pela forma de produção sob encomenda, com uso de máquinas mais simples e que empregam tecnologia mais baixa, diferentemente do adotado na produção seriada. As marcenarias utilizavam grande número de espécies nativas, de acordo com seus proprietários, que as chamavam pelo seu nome vulgar, sendo estas provenientes, em geral, de localidades próximas ou, então, da Região Norte do Brasil. Embora houvesse grande consumo de espécies nativas existia também um uso intensivo do Pinus, realizado por mais de $70 \%$ das marcenarias (Quadro 1).

Tabela 1. Percentual de marcenarias de Viçosa-MG de acordo com a espécie florestal utilizada

\begin{tabular}{|c|c|c|c|}
\hline Espécie & $\%$ & Espécie & $\%$ \\
\hline Cumaru & - & Angico & - \\
\hline Pinus..... & 76,47 & 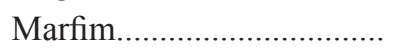 & 29,41 \\
\hline Louro & - & Angelim-margoso & - \\
\hline 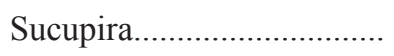 & 70,58 & 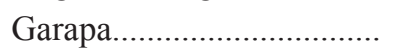 & 17,64 \\
\hline Cedrinho & - & 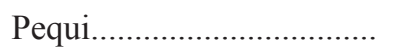 & 11,76 \\
\hline Cedrorana & - & Cedro & - \\
\hline 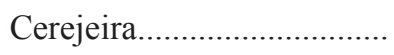 & 64,70 & Freijó & - \\
\hline Angelim-pedra & - & Ipê & - \\
\hline Eucalipto & - & Jequitibá-rosa & - \\
\hline 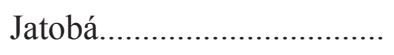 & 58,82 & Macaúba & - \\
\hline Mogno & - & 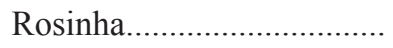 & 5,88 \\
\hline 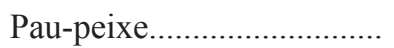 & 41,17 & & \\
\hline
\end{tabular}


Amadeira de Pinus era oriunda principalmente do Estado do Paraná e adquirida na sua grande maioria, na maior marcenaria da cidade que funciona como um entreposto comercial. Com esta espécie são feitos móveis, caixas e diversos materiais.

Com relação à madeira de Eucalipto, verificou-se que era adquirida em cidades próximas a Viçosa. Os empresários não consideravam a madeira apropriada para fabricação de móveis e não existe demanda por parte do consumidor.

Os resultados obtidos indicaram que as marcenarias locais consomem pouca madeira oriunda de reflorestamento (Pinus e Eucalipto), quando comparada ao uso de madeira nativa, e reflete uma tendência que ocorre nesta região. Em estudo realizado por Teixeira (2005), verificou-se que, no pólo moveleiro de Ubá, região circunvizinha à cidade de Viçosa, apenas 16,8\% do consumo de madeira maciça era proveniente de reflorestamento.
Os marceneiros demonstraram uma resistência em adotar o Eucalipto como substituto de madeiras nativas, pois julgavam que estas eram "mais atraentes aos consumidores", e, em certa parte, mais fáceis de serem "trabalhadas" apesar de mais caras. Também alegavam que a madeira de Eucalipto fornecida era de qualidade ruim e, por conseguinte, inadequada à fabricação de móveis, sendo utilizada apenas como sustentação e reforço nos móveis.

\section{Principais máquinas utilizadas}

As principais máquinas utilizadas pelas marcenarias, em seu processo produtivo, foram a desempenadeira, furadeira, lixadeira e serra circular.

Verificou-se que cada marcenaria tem, em média, dez tipos de máquinas diferentes, que executam as mais variadas funções. A desempenadeira, furadeira, lixadeira e serra circular eram os tipos de máquinas utilizadas em todas as marcenarias da cidade (Quadro 2).

Tabela 2. Percentual de marcenarias de Viçosa-MG de acordo com o tipo de máquina utilizada

\begin{tabular}{|c|c|c|c|}
\hline Máquina & $\%$ & Máquina & $\%$ \\
\hline Desempenadeira (plaina) & - & 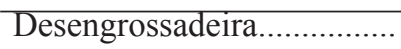 & 64,70 \\
\hline Furadeira & - & Torno............................ & 47,05 \\
\hline Lixadeira & - & 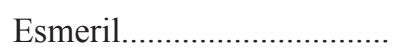 & 11,76 \\
\hline Serra circular............................ & 100,00 & Afiador & - \\
\hline 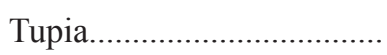 & 94,11 & Policorte & - \\
\hline Prensa......................................... & 88,23 & 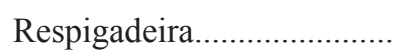 & 5,88 \\
\hline 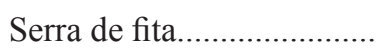 & 76,47 & & \\
\hline
\end{tabular}

Segundo os empresários a maioria das máquinas de suas fábricas foram adquiridas desde a fundação da empresa, muitas delas com tempo superior a 30 anos. Com relação à manutenção das máquinas, houve uma diversidade de respostas: a manutenção podia ser semanal, mensal ou anual, de acordo com o tipo de máquina e sua função. As peças para reposição eram compradas no mercado local.

\section{Produtos fabricados pelas marcenarias}

Com relação aos produtos fabricados pelas marcenarias de Viçosa, verificou-se que os tipos de móveis produzidos são heterogêneos, compreendendo desde móveis como estantes e guarda-roupas, até a fabricação de carros de boi, porteiras e outras utilidades rurais (Quadro 3). Este resultado demonstra a característica principal das marcenarias de Viçosa: fabricação de móveis e objetos de madeira, de acordo com a necessidade específica dos consumidores. 
Tabela 3. Percentual de marcenarias de Viçosa-MG de acordo com o tipo de produto fabricado

\begin{tabular}{|c|c|c|c|}
\hline Produto & $\%$ & Produto & $\%$ \\
\hline Estante & - & Armário para banheiro........ & 23,53 \\
\hline Guarda-roupa & 70,58 & 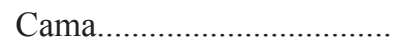 & 17,64 \\
\hline Mesa com cadeiras............. & 64,70 & Armário embutido & - \\
\hline Cômoda & - & 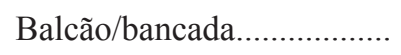 & 11,76 \\
\hline 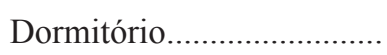 & 58,82 & Armário de quarto & - \\
\hline Armário de cozinha & 47,05 & Bancos & - \\
\hline Divisórias & - & Carro de boi & - \\
\hline 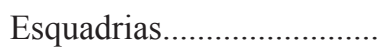 & 35,29 & Porteira............................... & 5,88 \\
\hline
\end{tabular}

Os produtos de acabamento, utilizados na confecção final do móvel, em 94,11\% dos casos, são adquiridos fora da cidade, principalmente oriundos de Ubá. Os marceneiros consideravam que os móveis produzidos por suas fábricas tinham um aspecto "atraente", de boa qualidade, porém entendiam que, como o processo era totalmente artesanal, a entrega do produto ao consumidor se tornava lenta e isso poderia se constituir num aspecto negativo ao efetuar uma venda.

Com relação ao destino dos resíduos, os resultados demonstraram que a maior parte se destina à granjas de frangos $(70,58 \%)$.

\section{Mercado atuante}

O principal destino dos produtos fabricados pelas marcenarias era a própria cidade de Viçosa-MG e em alguns casos também existia uma demanda nas cidades circunvizinhas. A divulgação das empresas e seus produtos ocorre de forma simples, sem qualquer tipo de propaganda institucionalizada, por meio dos próprios clientes. A escolha do tipo e "design" do produto é feito, na maioria dos casos, pelos próprios clientes ou então pela empresa, o que na prática, se constitui em cópia pura e simples de outros móveis já existentes. A cópia também poderia ser feita a partir de revistas especializadas ou websites (Figura 3). Tal fato contribuía para imprimir, ainda mais, o caráter artesanal e sob encomenda dos móveis produzidos nas marcenarias.

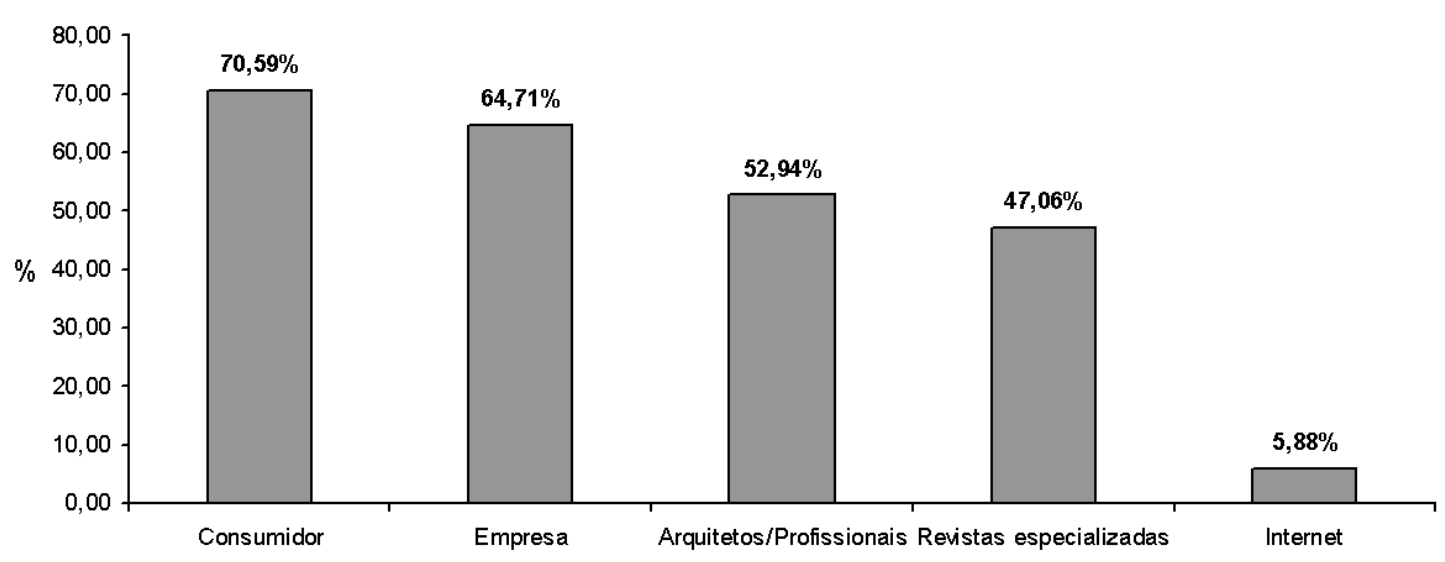

Gráfico 3. Principais responsáveis pelo tipo e "design" dos móveis produzidos pelas marcenarias da cidade de Viçosa, MG. 
Pouco mais da metade das empresas relatou que os móveis fabricados poderiam ser desenhados por profissionais ligados à área como arquitetos e decoradores. No entanto, salientaram que era o próprio cliente que contratava este profissional para desenvolver o design do produto.
Com relação aos possíveis inibidores de suas atividades foi destacado que a competição acirrada entre as empresas era o maior entrave, principalmente devido ao fato de disputarem o mercado com os móveis seriados, provenientes principalmente do Pólo Moveleiro de Ubá, com preços mais baratos (Figura 4).

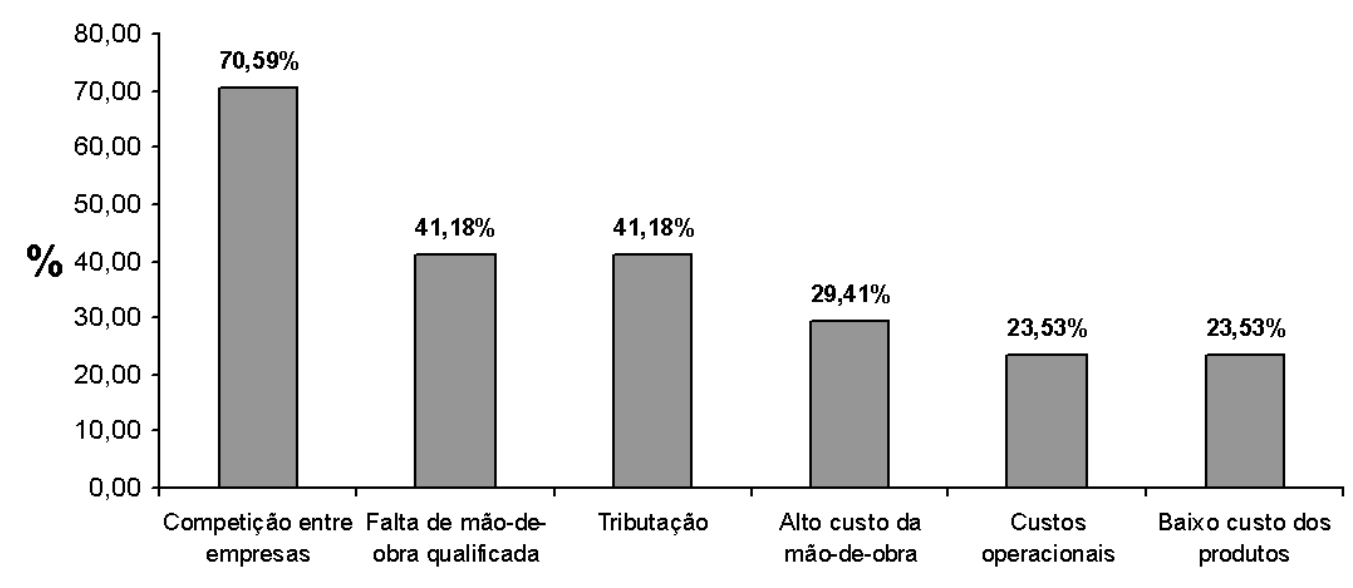

Gráfico 4. Principais inibidores da atividade de marcenaria na cidade de Viçosa, MG.

Para os empresários existia uma competição desonesta, pois empresas legalizadas concorriam com empresas informais, e aquelas incorriam em diversos custos, como registro de funcionários, por exemplo, que não havia para as informais. Além disso, foi destacada a falta de mão-de-obra qualificada do setor, o que obriga a própria marcenaria a fazer o treinamento, que muitas vezes é inadequado. Este treinamento, em geral, também é repassado no decorrer das gerações, de pai para filho.

Os empresários em sua maioria $(76,47 \%)$, não participavam de feiras e exposições de móveis, nem mesmo como visitantes. Desta forma, notouse que estão alheios às mais recentes inovações e tendências da indústria moveleira prejudicando mais uma vez o progresso deste setor na cidade. Dentre os empresários que visitam feiras de móveis $(35,29 \%)$, verificou-se que a principal feira visitada era a Feira de Móveis de Minas Gerais (FEMUR), do pólo moveleiro de Ubá-MG, distante cerca de 60 $\mathrm{km}$ de Viçosa.

Segundo os empresários o diferencial dos móveis produzidos em Viçosa em relação aos móveis seriados era a matéria-prima utilizada nos mesmos, destacando-se o uso de madeira maciça, geralmente oriunda de florestas nativas. Paralelamente a este fato, consideraram que a produção sob encomenda também traz benefícios para o setor, pois o móvel era personalizado de acordo com a preferência do consumidor.

No tocante à certificação florestal, que para $70 \%$ das empresas moveleiras certificadas no Brasil era uma estratégia importante para alavancar vendas e que para as empresas exportadoras no pólo de UbáMG era um objetivo a se alcançar (ALVES et al., 2007; JACOVINE et al., 2006a, 2006b), a maioria dos empresários da área de marcenaria de Viçosa desconhecia seu real significado. Apesar de estarem 
em contato com representantes, distribuidores e fornecedores, em sua maioria (70,59\%), não sabiam o seu significado, confundindo a certificação com a legalização da madeira que é liberada por órgãos, como Instituto Brasileiro do Meio Ambiente e Recursos Renováveis (IBAMA) e Instituto Estadual de Florestas (IEF). Estes resultados são semelhantes aos encontrados no estudo de Alves (2005) no pólo moveleiro de Ubá.

\section{Perspectivas do setor de marcenaria em Viçosa}

Para pouco mais da metade dos empresários pesquisados a possibilidade de maior participação futura nas vendas de móveis em Viçosa era possível (Figura 5).

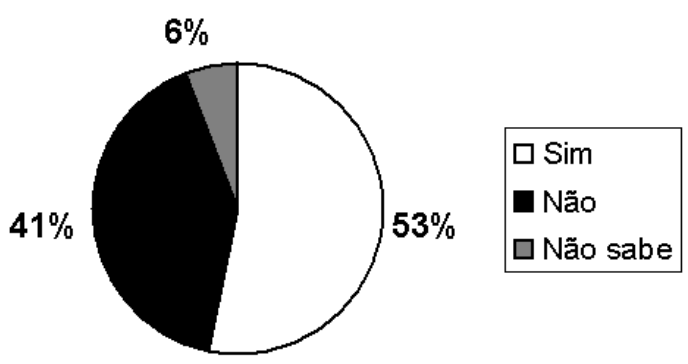

Gráfico 5. Percentual de empresários que julgavam possível uma maior participação futura em vendas de móveis no mercado de Viçosa.

Dentre os que consideram esta viabilidade plausível, os principais argumentos foram que os móveisfabricadosem Viçosapossuíamumdiferencial por serem artesanais e feitos de madeira maciça. Todavia, destacaram a necessidade de uma melhor organização do setor através de uma cooperativa ou associação que defendem os interesses do grupo e, também, de um ostensivo apoio do SEBRAE local. Além disso, a possibilidade de exposição dos móveis locais também foi citada como uma oportunidade de promoção destes produtos, apesar de já ter sido tentada anteriormente, através de uma antiga associação de marceneiros da cidade. Dificuldades de organização, custo de aluguel e a própria exposição do móvel, visto que somente fabricam por encomenda, eram os empecilhos destacados para a realização deste evento.

Para os $41 \%$ que consideraram a possibilidade de aumento das vendas remota, a principal razão era que os produtos fabricados em Viçosa não conseguiam competir principalmente com relação ao preço com móveis vindos de outros lugares, notadamente do pólo de Ubá-MG. Estes produtos, feitos de painéis reconstituídos, eram vendidos nas lojas de móveis da cidade. Além do preço, estas lojas conseguiam oferecer aos consumidores condições de pagamento mais favoráveis, facilitando a compra do móvel. A falta de organização do setor e de apoio de entidades governamentais também foi apontada por este grupo como empecilhos ao desenvolvimento das marcenarias. A maioria dos empresários (47,05\%) acreditava que seria possível que instituições, como a prefeitura local e a Universidade Federal de Viçosa, dessem preferência a compra de móveis produzidos na cidade. O restante dos empresários ou não acredita nesta possibilidade ou não tem opinião formada a respeito.

\section{Alternativas de melhoria e ampliação}

Com a inauguração, em 2006, do Laboratório de Propriedades Físicas da Madeira (LPM) da Universidade Federal de Viçosa, que está capacitado para realizar testes físicos, químicos, anatômico e mecânicos em madeira, além de usinagem, secagem e preservação, espera-se que possa haver uma maior interação entre a instituição e as marcenarias da cidade, visto que o laboratório estará mais voltado para pesquisas ligadas à indústria moveleira e construção civil.

Ademais, a organização dos empresários contribuiria para formalizar suas ações junto a órgãos como sindicatos, prefeitura e a própria universidade, bem como realização de eventos para divulgação de seus produtos. 


\section{Conclusões}

Pelos resultados apresentados neste trabalho, pode-se concluir que:

As marcenarias, em sua totalidade, trabalham na forma sob encomenda, com máquinas simples, e utilizam intensamente a madeira maciça no processo produtivo, notadamente oriunda de florestas nativas.

Tanto os empresários quanto os funcionários possuíam baixo grau de instrução, além de seus móveis não possuírem "design" próprio e serem heterogêneos, variando desde guarda-roupas até carros-de-boi e porteiras.

A concorrência, principalmente a informal, representaomaiorempecilhopara odesenvolvimento do setor, além das lojas de móveis que vendem produtos seriados vindos de outras localidades;

Há necessidade de uma maior qualificação, tanto gerencial quanto técnica, para aperfeiçoamento da atividade. Além disso, torna-se necessário uma maior organização através de associações e apoio de entidades, como o SEBRAE local, bem como da divulgação dos produtos aos consumidores locais.

\section{Referências}

ALVES, R. R. A certificação florestal na indústria moveleira nacional com ênfase no Pólo de Ubá, $M G$. 2005. Dissertação. (Mestrado em Ciência Florestal) Universidade Federal de Viçosa, Viçosa.

ALVES, R. R.; JACOVINE, L. A. G.; SILVA, M. L.; VALVERDE, S. R. Certificação florestal na visão gerencial e estratégica do Pólo Moveleiro de Ubá, MG. Revista Cerne, Lavras, v. 13, n. 1, p. 117-122, 2007.

CROCCO, M.; SANTOS, F.; SIMÕES, R.; HORÁCIO, F. Pesquisa industrialização descentralizada: sistemas industriais locais. $\mathrm{O}$ arranjo produtivo moveleiro de Ubá - MG. Belo Horizonte: CEDEPLAR, 2001.

FERNANDES, C. L. L.; OLIVEIRA JÚNIOR, R. H. Cluster no setor moveleiro: um estudo das potencialidades da região de Ubá (MG). Belo Horizonte: UFMG, 2002.
GORINI, A. P. F. Panorama do setor moveleiro no Brasil, com ênfase na competitividade externa a partir do desenvolvimento da cadeia industrial de produtos sólidos de madeira. São Paulo: BNDES, 1999.

INSTITUTO EUVALDO LODI - IEL. (Org.). Diagnóstico do pólo moveleiro de Ubá e região. Belo Horizonte: IEL/INTERSIND/SEBRAE, 2003.

JACOVINE, L. A. G.; ALVES, R. R.; VALVERDE, S. R.; SILVA, M. L. Certificação florestal na visão gerencial e estratégica da indústria moveleira nacional. Revista Semina: Ciências Agrárias, Londrina, v. 27, n. 3, p. 363374, 2006a.

JACOVINE, L. A. G.; ALVES, R. R.; VALVERDE, S. R.; SILVA, M. L.; NARDELLI, A. M. B.; SOUZA, A. P. Processo de implementação da certificação florestal nas empresas moveleiras nacionais. Revista Árvore, Viçosa, v. 30, n. 6, p. 961-968, 2006b.

LIMA, E. S. Novos rumos e desafios da indústria moveleira. In: SEMINÁRIO INTERNACIONAL SOBRE PRODUTOS SÓLIDOS DA MADEIRA DE ALTA TECNOLOGIA, ENCONTRO SOBRE TECNOLOGIAS APROPRIADAS DE DESDOBRO, SECAGEM E UTILIZAÇÃO DA MADEIRA DE EUCALIPTO, 1., 1998, Belo Horizonte. Anais... Viçosa: SIF/UFV/DEF, 1998. p. 119-124.

MAJOLA, F. M. A criatividade na formação de recursos humanos para a indústria moveleira. In: SEMINÁRIO DE PRODUTOS SÓLIDOS DE MADEIRA DE EUCALIPTO, 3., 2005, Vitória. Anais... Viçosa: SIF/ UFV/DEF, 2005. p. 1-13.

SERVIÇO BRASILEIRO DE APOIO ÀS MICRO E PEQUENAS EMPRESAS - SEBRAE. Critério de classificação das empresas. Disponível em: $<$ http://www. sebrae.com.br>. Acesso em: 5 ago. 2006.

TEIXEIRA, T. O. B. A percepção sobre o uso da madeira de eucalipto pelos fabricantes do pólo moveleiro de Ubá, MG. 2005. Dissertação. (Mestrado em Ciência Florestal) - Universidade Federal de Viçosa, Viçosa.

VALENÇA, A. C. V.; PAMPLONA, L. M. P.; SOUTO, S. W. Os novos desafios para a indústria moveleira no Brasil. BNDES Setorial, Rio de Janeiro, n. 15, p. 83-96, mar. 2002. 
